Article

\title{
Effect of Surface Modification with Different Acids on the Functional Groups of AF 5 Catalyst and Its Catalytic Effect on the Atmospheric Leaching of Enargite
}

\author{
Fazel G. Jahromi * and Ahmad Ghahreman *(1) \\ Robert M. Buchan Department of Mining, Queen's University, 25 Union Street, Kingston, ON K7L-3N6, Canada \\ * Correspondence: Fazel.Jahromi@queensu.ca (F.G.J.); Ahmad.G@queensu.ca (A.G.); \\ Tel.: +1-613-533-3294 (A.G.)
}

Received: 3 March 2019; Accepted: 15 April 2019; Published: 17 April 2019

check for updates

\begin{abstract}
Carbon-based catalysts can assist the oxidative leaching of sulfide minerals. Recently, we presented that AF 5 Lewatit ${ }^{\circledR}$ is among the catalysts with superior enargite oxidation capacity and capability to collect elemental sulfur on its surface. Herein, the effect of acid pre-treatment of the AF 5 catalyst was studied on the AF 5 surface, to further enhance the catalytic properties of AF 5 . The AF 5 catalyst was pretreated by hydrochloric acid, nitric acid and sulfuric acid. The results showed that the acid treatment drastically changes the surface properties of AF 5 . For instance, the concentration of quinone-like functional groups, which are ascribed to the catalytic properties of AF 5 , is $45.4 \%$ in the sulfuric acid pre-treatment AF 5 and only $29.8 \%$ in the hydrochloric acid-treated AF 5 . Based on the C 1s X-ray photoelectron spectroscopy (XPS) results the oxygenated carbon is $30.6 \%$ in the sulfuric acid-treated AF 5, 29.2\% in the nitric acid-treated AF 5 and $28.3 \%$ in the hydrochloric acid-treated AF 5 . The nitric acid pre-treated AF 5 resulted in the highest copper recovery during the oxidative enargite leaching process, recovering $98.8 \%$ of the copper. The sulfuric acid-treated AF 5 recovered $97.1 \%$ of the enargite copper into the leach solution. Among different leaching media and pre-treatment the lowest copper recovery was achieved with the $\mathrm{HCl}$ pre-treated $\mathrm{AF} 5$ which was $88.6 \%$. The pre-treatment of AF 5 with acids also had modified its elemental sulfur adsorption capacity, where the sulfur adsorption on AF 5 was increased from $30.9 \%$ for the $\mathrm{HCl}$ treated AF 5 to $51.1 \%$ for the sulfuric acid-treated AF 5 .
\end{abstract}

Keywords: enargite; carbon based catalyst; surface chemistry; copper; leaching; AF 5; catalytic leaching; sulfur; XPS; atmospheric leaching; pyrite

\section{Introduction}

Carbon-based catalysts (CBCs), such as activated carbon (AC) and AF 5, are porous catalysts with high surface area and high chemical resistance. One of the important properties of the $\mathrm{CBC}$ is their oxidative properties in the presence of oxygen, making the $\mathrm{CBC}$ an efficient catalyst in the hydrometallurgical research [1,2]. Recently, AF 5 has been employed in hydrometallurgy leach processes to catalyze the oxidative leaching of refractory sulfide minerals such as enargite and pyrite $[1,2]$. The application of $\mathrm{CBC}$ during the enargite $\left(\mathrm{Cu}_{3} \mathrm{AsS}_{4}\right)$ leaching process in chloride media has shown and improved copper extraction from $69 \%$ (no AF 5) to $92 \%$ (with AF 5) in $96 \mathrm{~h}$ [1]. A product of enargite leaching process with AF 5 is elemental sulfur, which interestingly AF 5 is capable of adsorbing the elemental sulfur on its surface, which is referred to as sulfur collection process [1,2].

The catalytic properties of the CBC in the oxidative leach processes is resulted from to the functional groups on its surface [3-5]. The oxygen functional groups such as hydroquinone and 
quinone groups on $\mathrm{CBC}$ surfaces have been proven to facilitate reversible reduction oxidation (redox) reactions [3-5]. Through chemical pre-treatment processes it is possible to increase the density of the functional groups on the $\mathrm{CBC}$ surface and improve its catalytic properties. This is of high interest for chemical processing and extractive metallurgy industry as the chemical pre-treatment processes can be low cost processes to implement; often the pre-treatment process involves only reacting the CBC with an oxygenated acidic solution, such as sulfuric acid solution. In addition to the oxygen functionalities, the negatively charged nitrogen functionalities also can participate in the catalysis of the reactions [6]. Some of the oxygen functional groups that might be available on the surface of $C B C$ are shown in Figure 1.

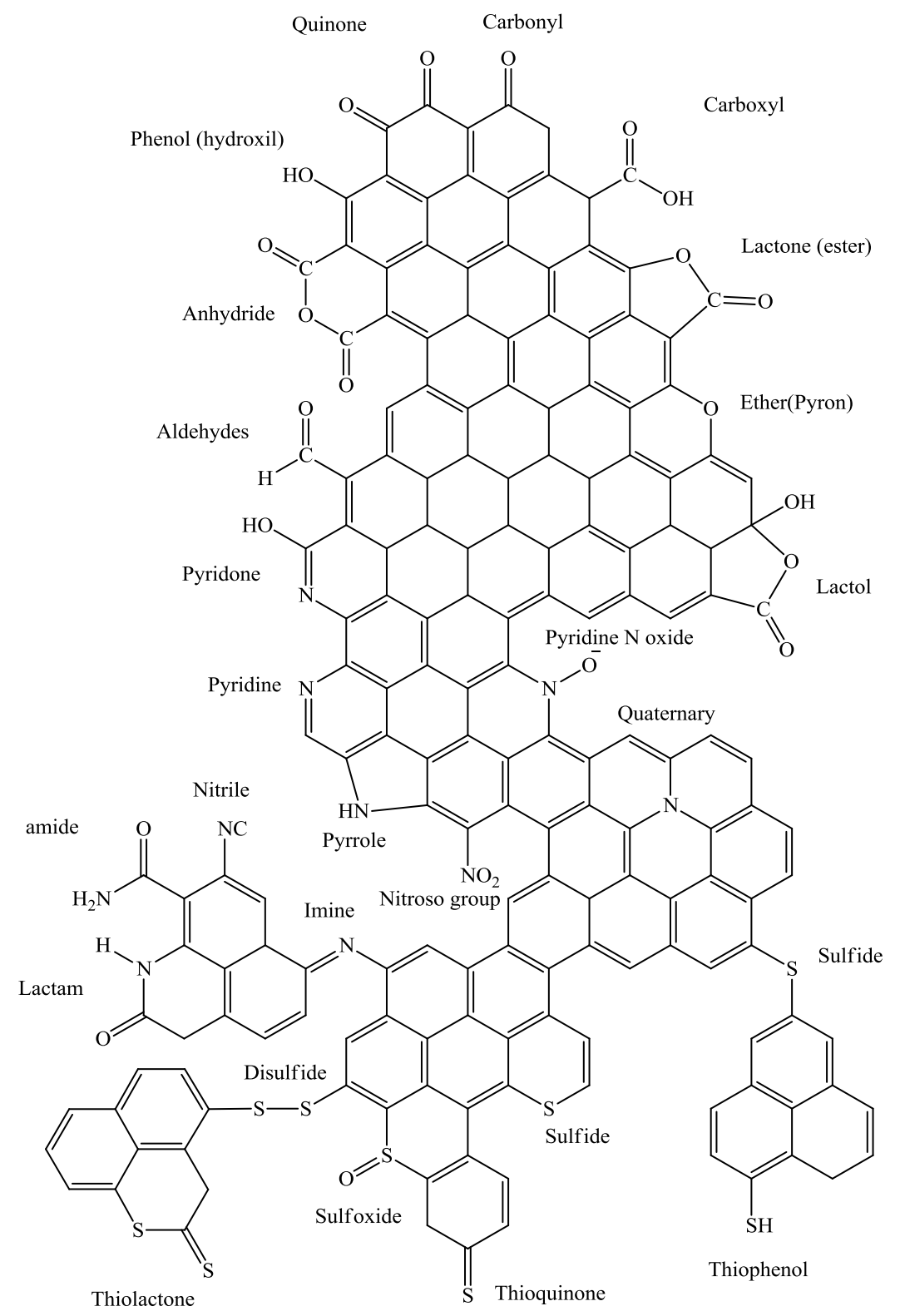

Figure 1. Oxygen, sulfur, and nitrogen functional groups on the surface of activated carbon.

A variety of $\mathrm{CBC}$ pre-treatment processes have been developed to further improve the density of functional groups on the $\mathrm{CBC}$ surfaces. $\mathrm{CBC}$ can be pre-treated with oxidative solutions of nitric acid, sulfuric acid, sodium hypochlorite, permanganate, bichromate, hydrogen peroxide, transition metals, and ozone-based gas mixtures, to its surface and generate oxygen functionalities [7-9]. During a nitric acid pre-treatment process the nitration mechanism and the generation of oxygen functionalities take 
place simultaneously [10]. The nitration treatment process can form nitrogen functionalities such as pyridine structures, nitro groups, pyrrole like groups, lactam, imides, amines, and pyridine-N-oxide species. It has been shown that the presence of the nitrogen functionalities on the CBC surface enhances its hydrogen sulfide and sulfur dioxide removal processes capabilities and increases its sorption capacity for anions [10]. The mechanism associated with the sulfur fixation is proposed to be through capillary condensation, adsorption, chemisorption, and solution in structure [10-15]. The CBC can be used to catalyze oxidative reactions such as the oxidative leaching of refractory sulfide minerals $[1,2]$. Ahumada et al. (2002) have shown that some $\mathrm{CBC}$ can produce in-situ $\mathrm{H}_{2} \mathrm{O}_{2}$ and $\mathrm{HO}_{2}{ }^{-}$in the presence of oxygen and water, and this phenomenon can be explained by the availability of chromene and quinone groups on the surface of the catalyst, as shown in Reactions (1) and (2) [16].

$$
\begin{aligned}
\mathrm{C}_{\text {Red }}^{*}+\frac{1}{2} \mathrm{O}_{2}+\mathrm{H}_{2} \mathrm{O} & \rightarrow \mathrm{H}_{2} \mathrm{O}_{2}+\mathrm{C}_{\mathrm{Ox}}^{*} \\
2 \mathrm{Fe}^{2+}+\mathrm{H}_{2} \mathrm{O}_{2}+2 \mathrm{H}^{+} & \rightarrow 2 \mathrm{Fe}^{3+}+2 \mathrm{H}_{2} \mathrm{O}
\end{aligned}
$$

The aim of the present study was to investigate the effect of different acidic chemical pre-treatment and leaching environments on the surface functional groups and oxidation capability of AF 5 . The AF 5 catalyst was pre-treated by three different acidic solutions: hydrochloric acid, nitric acid and sulfuric acid. The change in the type and concentration of different functionalities on the AF 5 surface, after each pre-treatment process, was studied. The pre-treated AF 5 catalysts were used to leach enargite mineral, to evaluate the effect of chemical pre-treatment of AF 5 on its catalytic properties for this specific hydrometallurgical process, i.e., enargite leaching. The effect of AF 5 pre-treatment was studied on the oxidative leaching of enargite. The AF 5 surface was studied with X-ray photoelectron spectroscopy (XPS) and infrared spectroscopy, before and after pre-treatment processes. In addition, the AF 5 efficiency in the leach tests was studied by the analysis of the leach test solutions to evaluate the copper dissolution efficiency, and the speciation of copper, iron, arsenic, and finally the sulfur adsorption by the AF 5 catalyst.

\section{Materials and Experimental Methods}

\subsection{Materials}

The carbon-based catalyst used in this study was AF 5 (Lewatit ${ }^{\circledR}$ ). Water-treated (fresh) and pre-treated AF 5 was used in the oxidative enargite leach tests to evaluate the impact of the pre-treatment process on the catalyst effectiveness by measuring the efficiency of the leach process. Examples of leach processes with AF 5 catalyst have been published before [1,2].

In this study an enargite concentrate containing $24.4 \%$ copper, $39.0 \%$ sulfur, $20.1 \%$ iron, and $8.5 \%$ arsenic was used as the raw material in the leach experiments. The head assay (ICP analysis) of the enargite sample is shown in Table 1. The results of Rietveld X-Ray Diffraction (XRD) analysis which was analyzed by Highscore Plus 4.0 software, confirmed that the concentrate includes $45.6 \%$ of enargite and $43.0 \%$ of pyrite. XRD results are presented in Table 2. Hydrated cupric chloride (Acros Organics, 99\%), hexahydrate ferric chloride (Sigma Aldrich, 98\%), pentahydrate ferric sulfate (Sigma Aldrich, 97\%), and sodium chloride (Fisher chemicals, 99\%) were used to prepare the test solutions.

Table 1. Head assay of enargite sample.

\begin{tabular}{ccccccc}
\hline Element & Copper & Iron & Arsenic & Sulfur & Zinc & Silver \\
\hline \multirow{2}{*}{ Composition } & & \multicolumn{5}{c}{ wt $\%$} \\
\cline { 2 - 6 } & 24.4 & 20.1 & 8.5 & 39.0 & 0.7 & ppm \\
\hline
\end{tabular}


Table 2. XRD results for head concentrate.

\begin{tabular}{ccc}
\hline Mineral & Chemical Formula & Mass\% \\
\hline Enargite & $\mathrm{Cu}_{3} \mathrm{AsS}_{4}$ & 45.6 \\
Pyrite & $\mathrm{FeS}_{2}$ & 43.0 \\
Sphalerite Iron & $(\mathrm{Zn}, \mathrm{Fe}) \mathrm{S}$ & 2.6 \\
Quartz & $\mathrm{SiO}_{2}$ & 2.5 \\
Chalcopyrite & $\mathrm{CuFeS}_{2}$ & 2.4 \\
Tennantite & $\left(\mathrm{Cu}, \mathrm{Fe}_{12} \mathrm{As}_{4} \mathrm{~S}_{13}\right.$ & 1.4 \\
Bornite & $\mathrm{Cu}_{5} \mathrm{FeS}_{4}$ & 0.8 \\
Arsenopyrite & $\mathrm{FeAsS}$ & 0.6 \\
Galena & $\mathrm{PbS}$ & 0.6 \\
Covellite & $\mathrm{CuS}$ & 0.5 \\
\hline Total & & $\mathbf{1 0 0 . 0}$ \\
\hline
\end{tabular}

\subsection{Pre-Treatment and Leaching Tests}

The AF 5 catalyst pre-treatment was performed by stirring the AF 5 in $1 \mathrm{~L}$ of $1 \mathrm{M}$ solution of the specific acids, nitric, hydrochloric and sulfuric acids, for $24 \mathrm{~h}$ at $25^{\circ} \mathrm{C}$. The treatment was followed by two washing stages with $1 \mathrm{~L}$ deionized, DI, water for $10 \mathrm{~min}$. The pre-treated AF 5 was then characterized and also was used as a catalyst in the leaching experiments.

The detailed procedure for the leach experiments have been published elsewhere [1,2]. The atmospheric leaching tests were systematically designed and carried out in 2-L jacketed glass reactors. A reflux condenser was used to prevent the excessive evaporation of water during the tests at high temperatures. In the leach tests $1 \mathrm{~L}$ of leach solution containing $0.5 \mathrm{M} \mathrm{HCl}$ and $24.85 \mathrm{~g} / \mathrm{L}$ hexahydrate ferric chloride, $13.69 \mathrm{~g} / \mathrm{L}$ hydrated cupric chloride and $65.57 \mathrm{~g} / \mathrm{L}$ sodium chloride was added into the reactor, along with $50 \mathrm{~g}$ of the enargite concentrate. The sulfuric acid leaching experiments were performed by using $1 \mathrm{~L}$ of $1 \mathrm{M} \mathrm{H}_{2} \mathrm{SO}_{4}$ solution with hydrated ferric sulfate. Tests were run at $90^{\circ} \mathrm{C}$, and slurry mixed by overhead mixer and oxygen was sparged to provide oxygen for the reactions. During the leach tests, often $96 \mathrm{~h}$ tests, a set of $15 \mathrm{~mL}$ samples were drawn from the solution using a syringe at $1,3,6,12,24,36,48,60,72,84$, and $96 \mathrm{~h}$. The solution loss was compensated by the addition of $15 \mathrm{~mL}$ of solution (average concentration of acid ferric, cupric). The samples were then centrifuged at $6000 \mathrm{rpm}$ for $10 \mathrm{~min}$ and filtered using $0.45 \mu \mathrm{m}$ syringe filters to separate the insoluble particles from the liquid phases. The filtrates were analyzed by an Agilent 4200 microwave plasma-atomic emission spectrometry (MP-AES) to measure the concentration of copper and iron. The concentration of wash-water was thereafter analyzed by MP-AES to quantify the concentration of copper and iron. The arsenic concentration for selected samples was analyzed by ICP-OES. Free acid titration was also performed on the samples in order to measure the free acid during the leaching. The leach solution was pressure filtered after $96 \mathrm{~h}$. The residue and catalyst were washed twice using $1 \mathrm{~L}$ of $10 \%$ respective acid, twice using $1 \mathrm{~L}$ of DI water and then dried in vacuum oven at $40^{\circ} \mathrm{C}$ for a week. The mineralogy of the solid residue was examined using XRD.

\subsection{Solid Analysis}

X-ray photoelectron spectroscopy (XPS) analysis was conducted by ThermoFisher Scientific $\mathrm{K}$-Alpha spectrometer with a monochromated $\mathrm{Al} \mathrm{K \alpha}$ X-ray source excitation $(1486.6 \mathrm{eV})$. The cold stage process with liquid nitrogen was performed to reduce the sulfur evaporation in vacuum chamber. The system uses a microfocused X-ray spot, ranging in size from $30 \mu \mathrm{m}$ to $400 \mu \mathrm{m}$, and the analysis in this study was done with a $400 \mu \mathrm{m}$ spot. The analysis chamber vacuum was in the range of $\sim 10-9$ mbar. The survey spectrum was typically acquired in a high pass energy $(200 \mathrm{eV})$, low point-density (1 point/eV) scanned mode. Regional spectra, used to determine relative atomic composition as well as for determination of chemical information, were acquired in a low pass energy $(50 \mathrm{eV})$, high point-density ( $0.1 \mathrm{eV}$ spacing) scanned mode. The energy scale of the instrument was established using 
sputter-cleaned $\mathrm{Au}, \mathrm{Cu}$, and $\mathrm{Ag}$. Accepted binding energy $(\mathrm{BE})$ value for the $\mathrm{Au} 4 \mathrm{f}\left(\mathrm{Au} 4 \mathrm{f}_{7 / 2}=84.0 \mathrm{eV}\right)$, $\mathrm{Cu} 2 \mathrm{p}\left(\mathrm{Cu} 2 \mathrm{p}_{3 / 2}=932.67 \mathrm{eV}\right)$ and $\mathrm{Ag} 3 \mathrm{~d}\left(\mathrm{Ag} \mathrm{3d} \mathrm{d}_{5 / 2}=368.26 \mathrm{eV}\right)$ transitions were used to establish absolute energy scale and linearity. After acquiring XP-spectra, XPS Peak 4.1 software was used for fitting the XPS peaks. FTIR analysis was performed by an ALPHA II Bruker DRIFT on powder samples. Samples were prepared by mixing the powder with $\mathrm{KBr}$ and pressurizing it to achieve a clear and consistent pellet. Carbon and sulfur content analyses were performed on the catalysts and residue samples using an ELTRA CS-2000 induction furnace.

\section{Results and Discussion}

\subsection{Pre-Treated AF 5 Surface Characterization}

\subsubsection{Infrared (IR) Spectroscopy Analysis}

The IR analysis was applied to study the surface of AF 5 before and after different pre-treatment processes. It is worth noting that the IR analysis is often carried out as a qualitative analysis method rather than a quantitative method [17]. The transmission IR spectra of water-treated AF 5 and hydrochloric, nitric and sulfuric acid-treated AF 5 are presented in Figure 2. In all of the measurements, a band of $\mathrm{O}-\mathrm{H}$ stretching vibrations exists between $3200-3600 \mathrm{~cm}^{-1}$. This band is related to the surface carboxylic groups and chemisorb water $[17,18]$. The adsorption bands at 1700 and in the 1570-1620 range, which were observed in all the catalyst analyses, are likely due to the stretching vibrations of $\mathrm{C}=\mathrm{O}$ in carboxylic, ester lactones, quinone and radical structures $[7,17,19,20]$. The absorption bands in the $1300-1000 \mathrm{~cm}^{-1}$ are likely ascribed to the overlapping peaks of absorption of ether, epi-oxide and phenolic structures existing in a different environment or existence of $\mathrm{C}-\mathrm{N}$ stretching vibrations overlapping the carbon structure [21]. The absorption band around $800 \mathrm{~cm}^{-1}$ can be the result of cyclic compounds containing $\mathrm{C}=\mathrm{C}$ and $\mathrm{C}=\mathrm{N}[17,22]$.

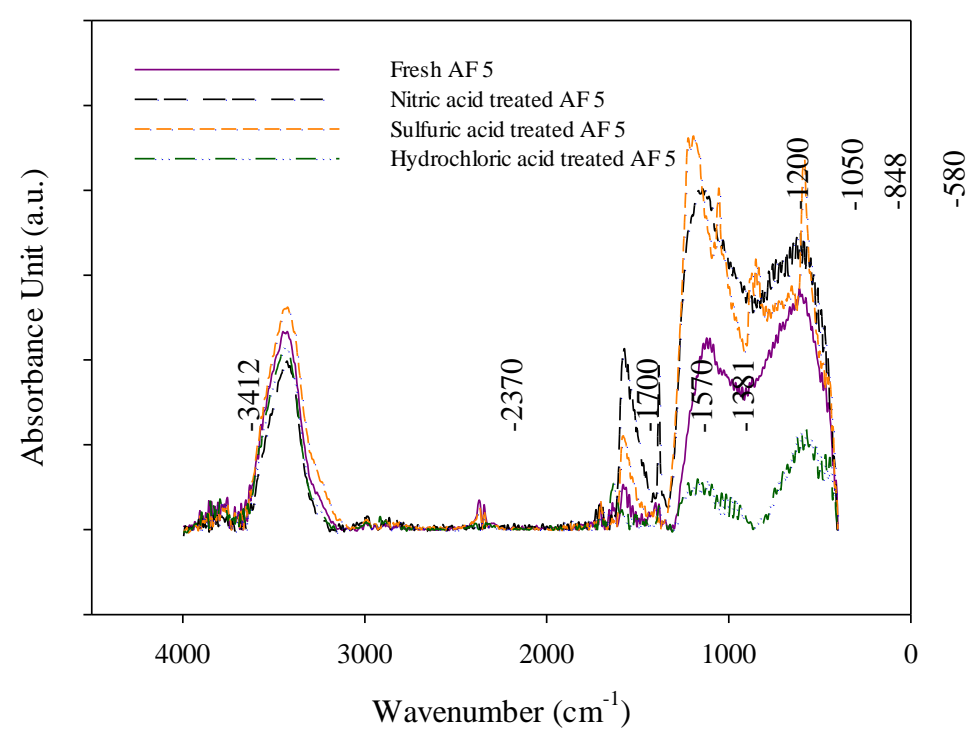

Figure 2. DRIFT spectra of the treated AF 5 in the $4000-450 \mathrm{~cm}^{-1}$ range.

The nitric acid treatment on $\mathrm{CBC}$ can evolve the oxygen containing functionalities and nitro groups on the surface of the carbonaceous materials which can be detected by absorption band in the range of $1330-1530 \mathrm{~cm}^{-1}[10,17]$. The nitric acid treatment can form the pyridine structure on the surface of the carbon. In the range of $1380-1470 \mathrm{~cm}^{-1}$ carboxyl carbonate structures absorption hydroxyl groups, $\mathrm{C}=\mathrm{C}-\mathrm{H}$ structures and $\mathrm{C}-\mathrm{N}$ vibrations can show up as the nitric acid-treated AF $5[10,17]$. The absorption sharp band at 1076-1014 $\mathrm{cm}^{-1}$ in sulfuric acid-treated AF 5 can be due to the C-O stretching band generated by the sulfuric acid oxidation process $[18,23]$. Also, the band at $590 \mathrm{~cm}^{-1}$ appeared 
in the sulfuric acid-treated AF 5 is related to the sulfate and bisulfate ions [24]. The nitric acid and sulfuric acid treatment of AF 5 resulted in the formation of the carboxylic structures and surface oxygen complexes [10].

\subsubsection{Surface Analysis by XPS}

The XPS analysis was also applied to evaluate the surface of AF 5 before and after different pre-treatment processes. The XPS spectra of water-treated (fresh) AF 5 catalyst indicated the presence of carbon, oxygen, silicon, and sulfur in the acid-treated samples, and nitrogen and chlorine in some of the samples based on the chemical treatment. The different detected species are presented in Figure 3. The XPS spectra of $\mathrm{O} 1 \mathrm{~s}$ excitation of AF 5 catalyst can be concluded of five main components of oxygen doubly bonded to carbon in quinone-like structures with binding energy of 531.0-531.9 eV [6,25], carbonyl, anhydrides and hydroxyl groups at 532.3-532.8 eV $[6,25,26]$, non-carbonyl oxygen atoms in anhydrides and esters at 533.1-533.8 eV [6,26], oxygen in carboxyl groups at 534.3-535.4 eV [26] and chemisorbed water or oxygen at 536.0-536.5 eV [6,10,25,26]. Most of the $\mathrm{O} 1 \mathrm{~s}$ deconvolution peaks are located between 531 and $534 \mathrm{eV}$, and shift of these peaks to a higher binding energy might be an indication of declining of the amide type or carboxylic groups or increasing of ethers and hydroquinone group. It is worth mentioning that in the characterization of oxygen functionalities, it is more convenient to use $\mathrm{C} 1 \mathrm{~s}$ instead of $\mathrm{O} 1 \mathrm{~s}$ electron peaks since the difference in binding energies of electronegative elements are quite small $[10,26]$. High resolution XPS spectra of $\mathrm{O} 1 \mathrm{~s}$ peak for different treatments of AF 5 are shown in Figure 4. For all of the AF 5 samples investigated, three forms of oxygen peaks can be found including: (1) oxygen peak in quinone-like structures observed at 530.8-531.3 eV [6,25], (2) carbonyl oxygen peaks in ester and anhydrides observed at 532.4-532.6 eV $[6,25,26]$, and (3) non-carbonyl oxygen atoms in ester and anhydrides which were found at $533.4-533.7 \mathrm{eV}[6,10,25,26]$.

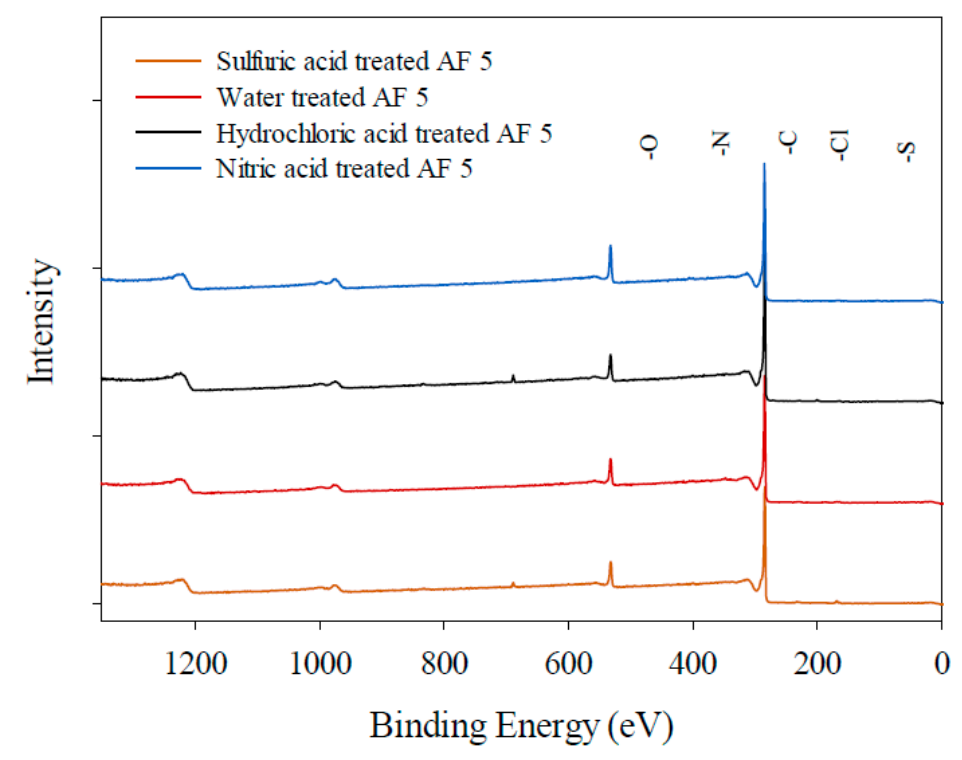

Figure 3. XPS spectra of AF 5 with different pre-treatment.

The relative content of oxygen peaks is reported in Table 3. In the water-treated samples, the $\mathrm{O} 1 \mathrm{~s}$ peak was deconvoluted to evenly distributed mix of peaks 1,2, and 3. By sulfuric acid treatment, the relative content of the peaks 1 and 3 was increased from $36.8 \%$ and $32.5 \%$ (water-treated) to $45.4 \%$ and $37.3 \%$ respectively, indicating an increase in the quinone-like structures and ester and quinine on the surface of AF 5. On the other hand, the hydrochloric acid treatment had declined the relative content of the quinone-like structures from 36.8 to $29.8 \%$. The other substantial change in the oxygen functional groups was attributed to the nitric acid treatment. The nitric acid pretreatment can also cause the 
formation of surface defects, increase the porosities and reveal fresh new surface with high potential of activation [26]. The relative content of peak 1 and 3 was declined significantly when the peak 2 content had increased from 30.7 to $49.0 \%$. This increase can be related to the oxygen and nitrogen bindings.

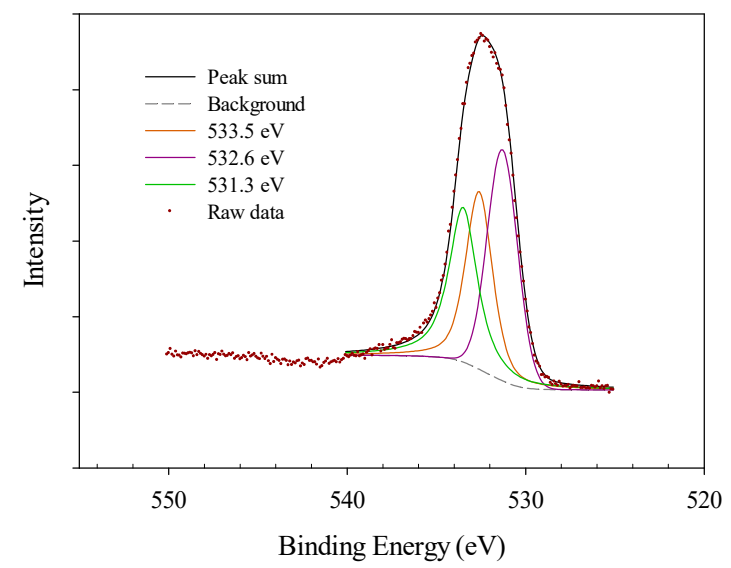

(a)

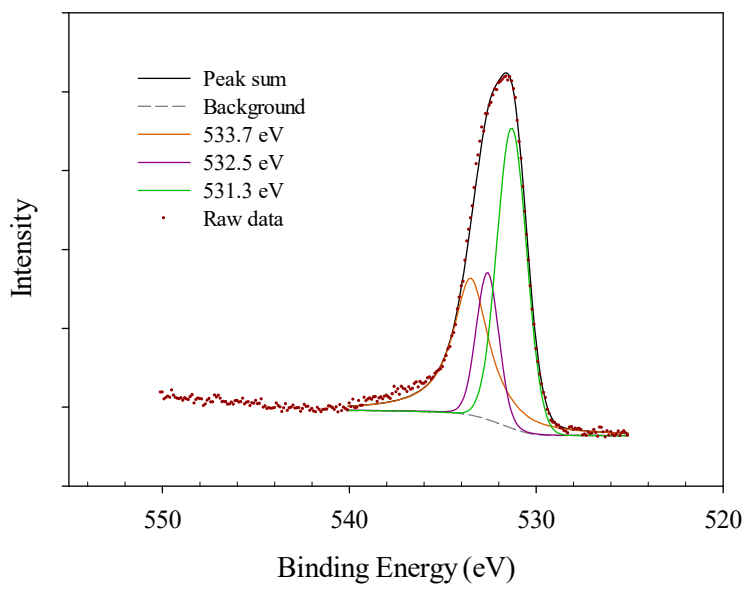

(c)

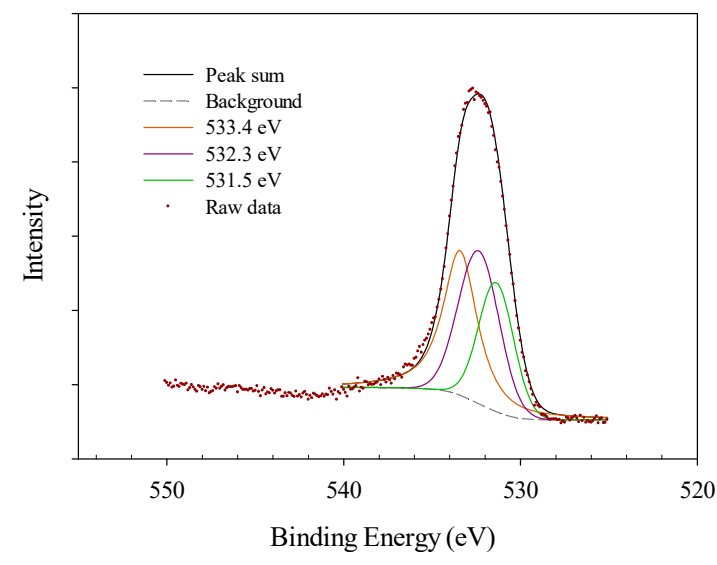

(b)

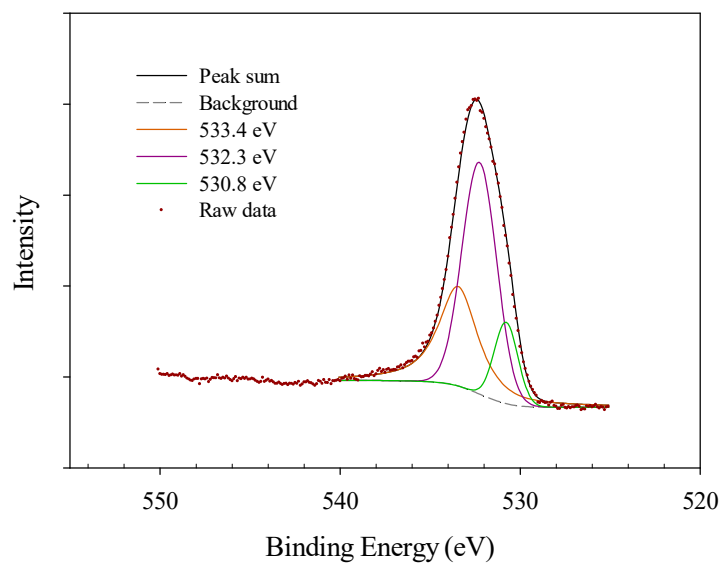

(d)

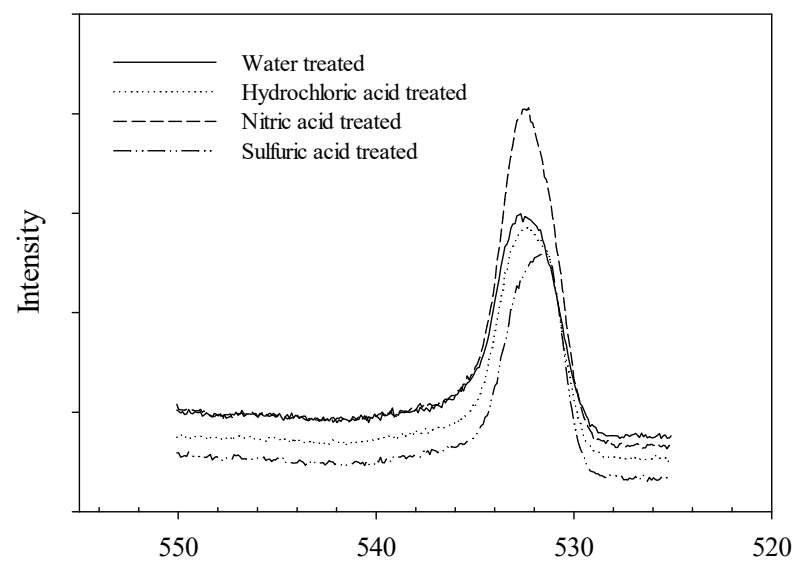

Binding Energy (eV)

(e)

Figure 4. XPS spectra of oxygen 1s peak for different AF 5 treatments: (a) Water-treated (b) Hydrochloric acid-treated, (c) Sulfuric acid-treated, (d) Nitric acid-treated, (e) Raw data comparison. 
Table 3. Relative content of functional groups in $\mathrm{O}$ 1s peak.

\begin{tabular}{cccc}
\hline \multirow{2}{*}{ Sample } & \multicolumn{3}{c}{ O 1s Relative Concentration (\%) } \\
\cline { 2 - 4 } & Peak 1 & Peak 2 & Peak 3 \\
\hline Water-treated & 36.8 & 30.7 & 32.5 \\
Hydrochloric & 29.8 & 33.9 & 36.3 \\
acid-treated & 45.4 & 17.3 & 37.3 \\
Sulfuric acid-treated & 23.5 & 49.0 & 27.5 \\
Nitric acid-treated & & & \\
\hline
\end{tabular}

The high resolution XPS spectra of S 2p 3/2 can contain up to 6 main peaks related to thiol, carbon bisulfide and SH group bonded to the phenol ring at 163.1-163.7 eV [6,10,24]; sulfides and thioether groups at $164.3 \mathrm{eV}[6,10,24]$; sulfoxides and sulfite groups at 167.5-167.2 eV [6]; sulfone at $168.0 \mathrm{eV}[10,24]$; and sulfate, sulfite, and sulfonic acid groups at $169 \mathrm{eV}[6,10,24]$. It should be noted that water-treated AF 5 contains $1.06 \%$ sulfur in its structure. In the water-treated AF 5 , four peaks were detected: (1) S 2P 3/2 peak of SH group bond to the phenol ring, polysulfide or elemental sulfur peak at 163.7 with (2) Peak $1 \mathrm{~S} 2 \mathrm{P} 1 / 2$ component at $164.9[6,10,24]$, (3) $\mathrm{R}_{2} \mathrm{~S}=\mathrm{O}, \mathrm{R}_{-} \mathrm{SO}_{2}-\mathrm{R}$ groups at $168 \mathrm{eV}$ (4) With S 2P 1/2 component at $169[6,10,24]$, and (5) $\mathrm{SO}_{4}{ }^{2-}, \mathrm{SO}_{3}{ }^{2-}$ ions, and $\mathrm{RO}_{2}-\mathrm{S}-\mathrm{S}-\mathrm{R}$ groups at $169 \mathrm{eV}[6,10,24]$. The hydrochloric acid treatment of AF 5 in Figure 5 clearly shows peaks 1 and 2; however, peaks 4 and 5 were not easy to detect which could be because of the dissolution process of the some of the sulfate or other types of sulfur species. The sulfuric acid-treated AF 5 showed the four general types of the sulfur peaks; nonetheless, the concentrations of peaks 3,4 and 5 showed an increase. Furthermore, nitric acid pretreatment did not make a considerable change in the type of sulfur functional groups; however, peaks 3,4 and 5 concentrations declined when peaks 1 and 2 increased compare to the water-treated AF 5.

The carbon 1s XPS spectra of carbon-based catalysts can be deconvoluted into several peaks including carbon with graphite structure at $284.5 \mathrm{eV}$ [6,24], carbon singly bonded to oxygen in phenols and ethers in the form of $(\mathrm{C}-\mathrm{O})$ at $286.1 \mathrm{eV}[10,24]$, carbon double bonded to oxygen $(\mathrm{C}=\mathrm{O})$ in ketones and quinones at $287.5 \mathrm{eV}$ [6], carbon nitrogen structures at 286.3-287.5 eV [10,24], carbonyls at $287.3 \mathrm{eV}[6,10,24]$, carbon bonded with two oxygens in the form of -COO such as carboxyls, esters and anhydrides at $288.7 \mathrm{eV}[6,10,24]$ and the shake-up line for carbon in aromatic compound $\left(\pi-\pi^{*}\right.$ transition) at $290.5 \mathrm{eV}$ [6,27-29]. It is likely that the peak at $284.5 \mathrm{eV}$ is partially originated from the adventitious carbon. As it is shown in Figure 6, all of the carbon peaks were observed in different treatments of AF 5, however, some shifts in peak positions were detected, specifically in the case of hydrochloric acid-treated AF $5[21,26,27]$. All of the above carbon deconvoluted XPS spectra for AF 5 samples are clearly including five main peaks of (1) graphitic carbon $[6,10,24]$, (2) carbon species in phenols, alcohol and ethers $[6,10,24]$, (3) carbon in quinones, ketones and carbonyls or carbon nitrogen bonding $[6,10,24],(4)$ carboxyl, anhydrides and ester groups [6,10,24], and (5) shake up satellite due to the transition in aromatic rings with a shift in some cases $[6,10,24]$, as shown in Figure 6. Based on the deconvoluted $\mathrm{C}$ 1s peak, the relative concentrations of different functional groups are demonstrated in Table 4. Peaks 2, 3, and 4 indicate the oxygenated carbon peaks, and an increase in the sum of those peaks indicates the efficient degree of oxidation by oxidative pretreatment [27]. In general, the sulfuric acid and nitric acid treatments had increased carboxylic and quinone-like structures and reduced the phenol type functional groups. The oxidative pretreatment likely oxidized graphite and phenolic groups to carboxylic and quinone-like structures [26]. 


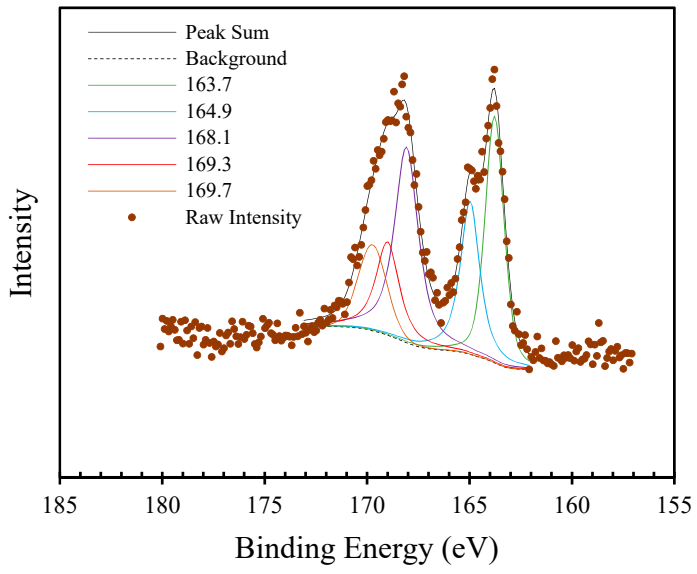

(a)

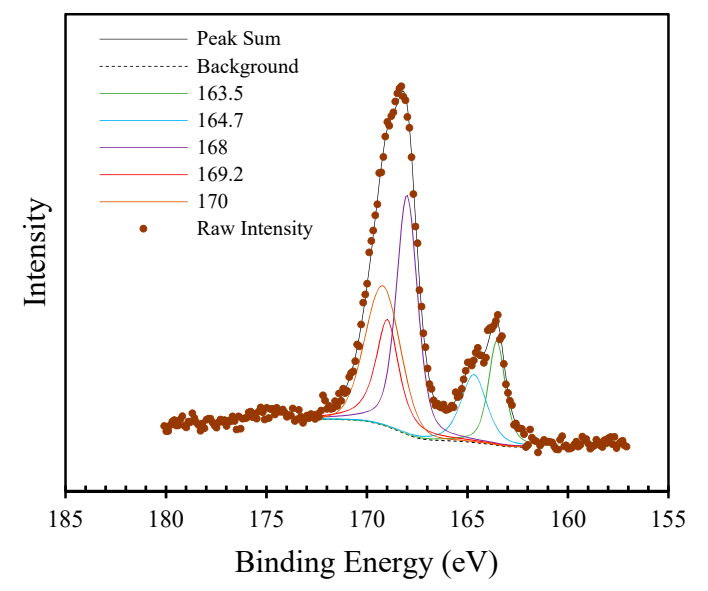

(c)

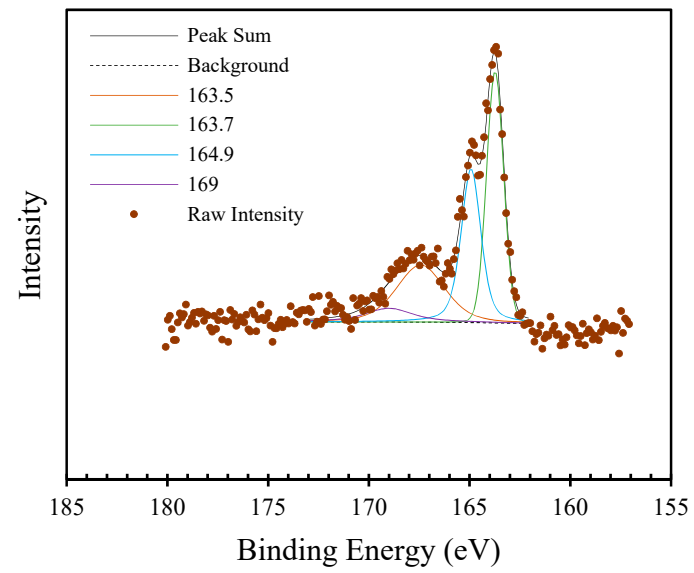

(b)

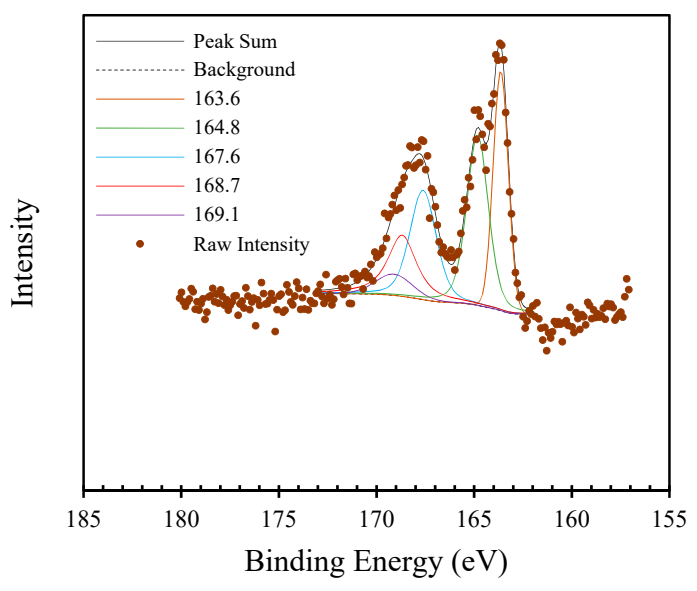

(d)

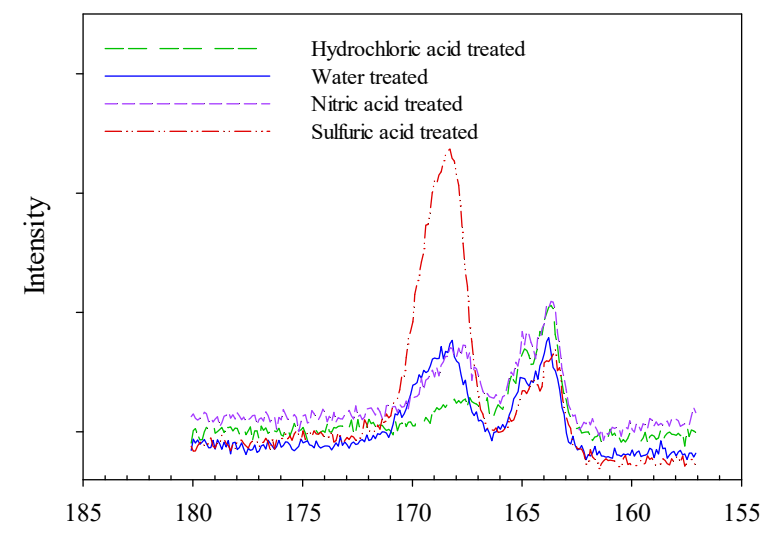

Binding Energy (eV)

(e)

Figure 5. XPS spectra of sulfur 2p peak for different AF 5 treatments: (a) Water-treated (b) Hydrochloric acid-treated, (c) Sulfuric acid-treated, (d) Nitric acid-treated, (e) Raw data comparison. 


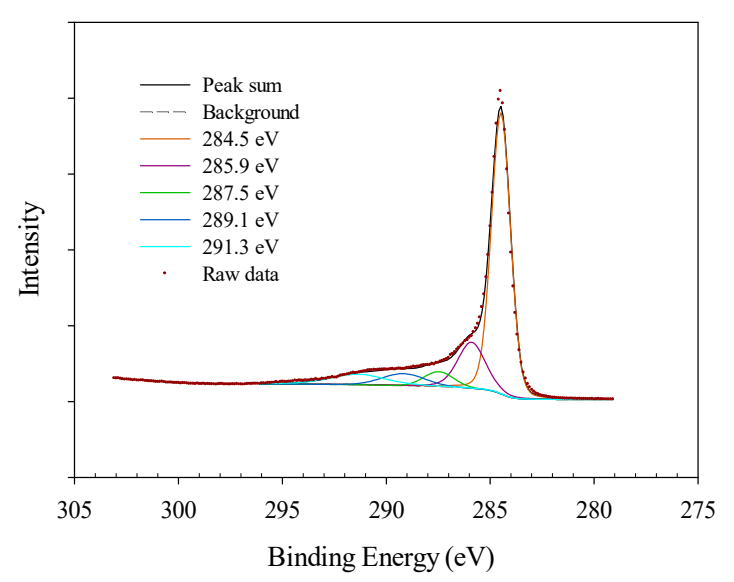

(a)

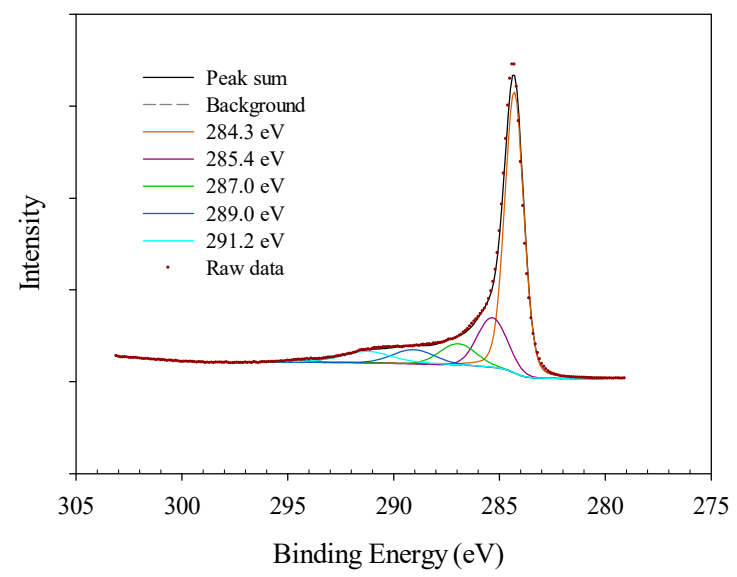

(c)

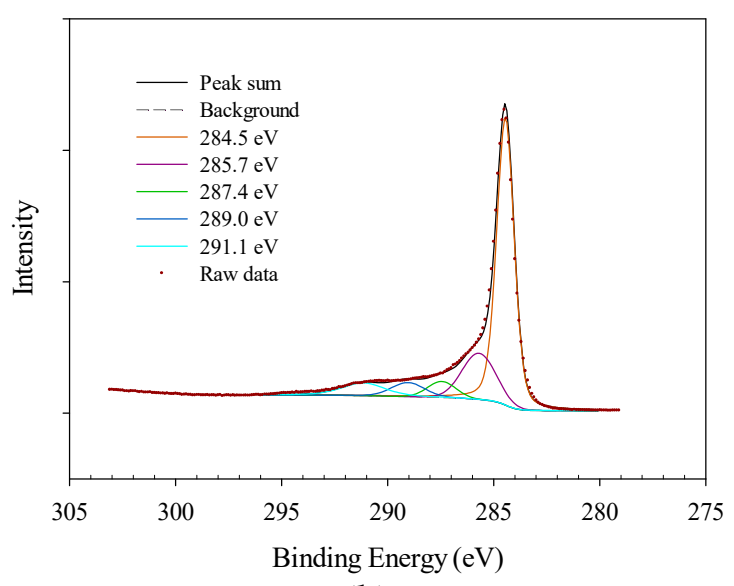

(b)

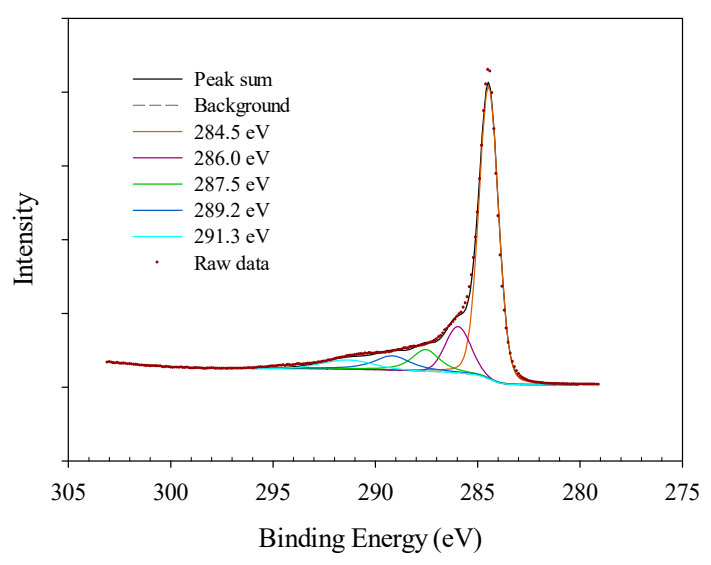

(d)

Figure 6. XPS spectra of carbon 1s peak for different AF 5 treatments (a) Water-treated (b) Hydrochloric acid-treated, (c) Sulfuric acid-treated, (d) Nitric acid-treated.

Table 4. Relative concentration of different groups in C 1s peak.

\begin{tabular}{ccccccc}
\hline \multirow{2}{*}{ Sample } & \multicolumn{6}{c}{ C 1s Relative Concentration (\%) } \\
\cline { 2 - 6 } & Peak 1 & Peak 2 & Peak 3 & Peak 4 & Peak 5 & $\begin{array}{c}\text { Oxygenated } \\
\text { Carbon }\end{array}$ \\
\hline Water-treated & 64.7 & 16.2 & 5.1 & 5.9 & 8.1 & 27.2 \\
Hydrochloric acid-treated & 64.3 & 17.7 & 5.1 & 5.6 & 7.3 & 28.3 \\
Sulfuric acid-treated & 61.8 & 15.9 & 8.3 & 6.5 & 7.5 & 30.6 \\
Nitric acid-treated & 65.7 & 12.8 & 8.7 & 7.7 & 5.1 & 29.2 \\
\hline
\end{tabular}

The analysis of $\mathrm{N}$ 1s of a carbon-based catalyst can be assigned to main peaks of pyrrolic nitrogen and pyridines in the form of (C-N-C) at 399.6-400.5 eV [6,10,24], quaternary (N-Q) nitrogen, protonated pyridinic, nitrogen atoms replacing carbon in graphene in the form of $\left(\mathrm{C}-\mathrm{N}^{+} \mathrm{H}-\mathrm{C}\right)$ at $401.3 \mathrm{eV}$, and oxidized nitrogen functionalities or $\mathrm{NO}_{2}$ groups at $402-405 \mathrm{eV}$ and $405.1 \mathrm{eV}$ (Figure 7) [6,24]. Nitrogen 1s excitation peak was only found in the nitric acid-treated AF 5 sample and deconvoluted to three main peaks at 405.6, 401.3 and $399.7 \mathrm{eV}[6,10,24]$ which is the characteristic of the above three peaks. The contribution of oxidized nitrogen functionalities is as high as $52.8 \%$ in this sample indicating the oxidation associated with the generation nitrogen functional groups on the surface of AF 5 by nitric acid oxidative pre-treatment. 


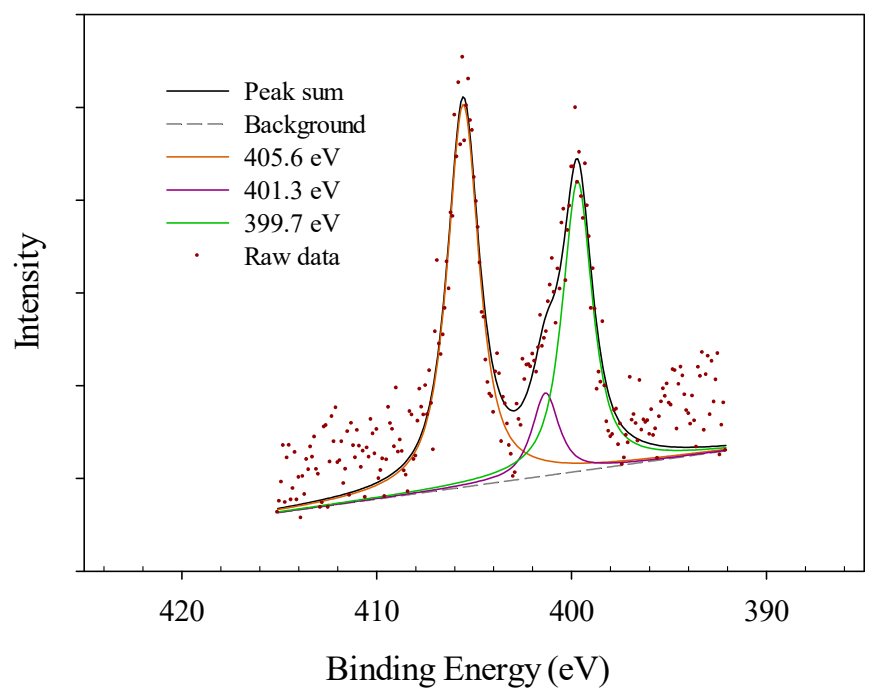

Figure 7. XPS spectra of nitrogen 1s peak for nitric acid-treated AF 5.

\subsubsection{Sulfur Analysis}

The sulfur content of the water-treated (fresh) and pre-treated AF 5 is listed in Table 5. Untreated AF 5 contains $1.06 \%$ of sulfur. The sulfur content in AF 5 had increased to $2.12 \%$ after the sulfuric acid treatment, whereas the hydrochloric acid and nitric acid treatments had removed sulfur from AF 5 reducing the AF 5 sulfur content to 0.97 and $0.88 \%$, respectively. The tendency of $C B C$ for sulfur adsorption has been previously shown, where the adsorption of hydrogen sulfide can proceed until the adsorbed sulfur blocks the porosities and prohibits further adsorption [10]. Surface analysis on different pre-treated AF 5 samples showed the availability of different functional groups such as oxygen, nitrogen and sulfur. The next step is to validate the effect of the above-mentioned functional groups in an actual leaching process and understand how the leaching solution composition and the pre-treatment process affects the catalytic properties of the $C B C$ and the copper leaching efficiency. It should be noted that the leaching in certain types of acid such as sulfuric acid or hydrochloric acid has a similar effect on the pre-treatment of the catalyst with that type of acid due to the availability of the same ions in the solution.

Table 5. Sulfur content in AF 5 samples.

\begin{tabular}{cc}
\hline Catalyst & Sulfur Content (\%) \\
\hline Water-treated (Fresh) AF 5 & 1.06 \\
Sulfuric acid-treated AF 5 & 2.12 \\
Hydrochloric acid-treated AF 5 & 0.97 \\
Nitric acid-treated AF 5 & 0.88 \\
\hline
\end{tabular}

\subsection{Effect of Catalyst Pre-Treatment and Leaching Media on Enargite Leaching}

\subsubsection{Oxidative Enargite Leaching with AF 5 catalyst}

The oxidative leaching of enargite in an acidic ferric sulfate solution can be presented by the following reactions $[30,31]$ :

$$
\begin{gathered}
\mathrm{Cu}_{3} \mathrm{AsS}_{4}+6 \mathrm{H}^{+}+2.75 \mathrm{O}_{2} \rightarrow 3 \mathrm{Cu}^{2+}+\mathrm{H}_{3} \mathrm{AsO}_{3}+4 \mathrm{~S}^{0}+1.5 \mathrm{H}_{2} \mathrm{O} \\
\mathrm{Cu}_{3} \mathrm{AsS}_{4}+3 \mathrm{H}_{2} \mathrm{O}+9 \mathrm{Fe}^{3+} \rightarrow 3 \mathrm{Cu}^{2+}+\mathrm{H}_{3} \mathrm{AsO}_{3}+4 \mathrm{~S}^{0}+3 \mathrm{H}^{+}+9 \mathrm{Fe}^{2+}
\end{gathered}
$$

It has been shown that AF 5 can catalyze the leaching Reactions [1,2]. The main purposes of the AF 5 application, as a catalyst in the enargite leaching process, are: (1) to increase the leaching process 
kinetics and extraction of the copper from the mineral to the pregnant leach solution (PLS), (2) to oxidize the arsenic in the leach solution, and (3) to collect the elemental sulfur product of the enargite leaching reaction on AF 5. As presented above, the pre-treatment of AF 5 with different acidic solutions changes the functional groups on its surface and so its catalytic effect on enargite oxidative leaching as well as the AF 5 capacity for the elemental sulfur adsorption. The type of dissolution media can also have an effect on the leaching kinetics. In order to study the effect of the catalyst pre-treatment and dissolution media, three sets of enargite leaching experiments were carried out: (a) leaching in sulfuric acid with water-treated AF 5, (b) leaching in hydrochloric acid with water-treated AF 5, and finally (c) leaching in sulfuric acid with nitric acid-treated AF 5. The leaching condition was similar in these experiments including $5 \mathrm{~g} / \mathrm{L}$ initial ferric with $50 \mathrm{~g}$ AF 5 at $90^{\circ} \mathrm{C}$. The copper recovery rates versus time are presented in Figure 8 for these test works. In sulfuric acid leaching cases, the dissolution of copper is comparable with nitric acid catalyst pre-treatment and with water-treated catalyst pre-treatment. The copper dissolution rate in sulfuric acid leaching had increased from $97.1 \%$ to $98.8 \%$ when the nitric acid pre-treated AF 5 was used. The copper recovery with the water-treated catalyst in hydrochloric acid was only $88.6 \%$ (Figure 8). The higher copper dissolution rate observed in the sulfuric acid leaching is due to the higher concentration of oxygen functional groups and nitrogen functionalities in sulfuric acid leaching and the nitric acid-treated AF 5 in sulfuric acid which was observed in XPS and IR study.

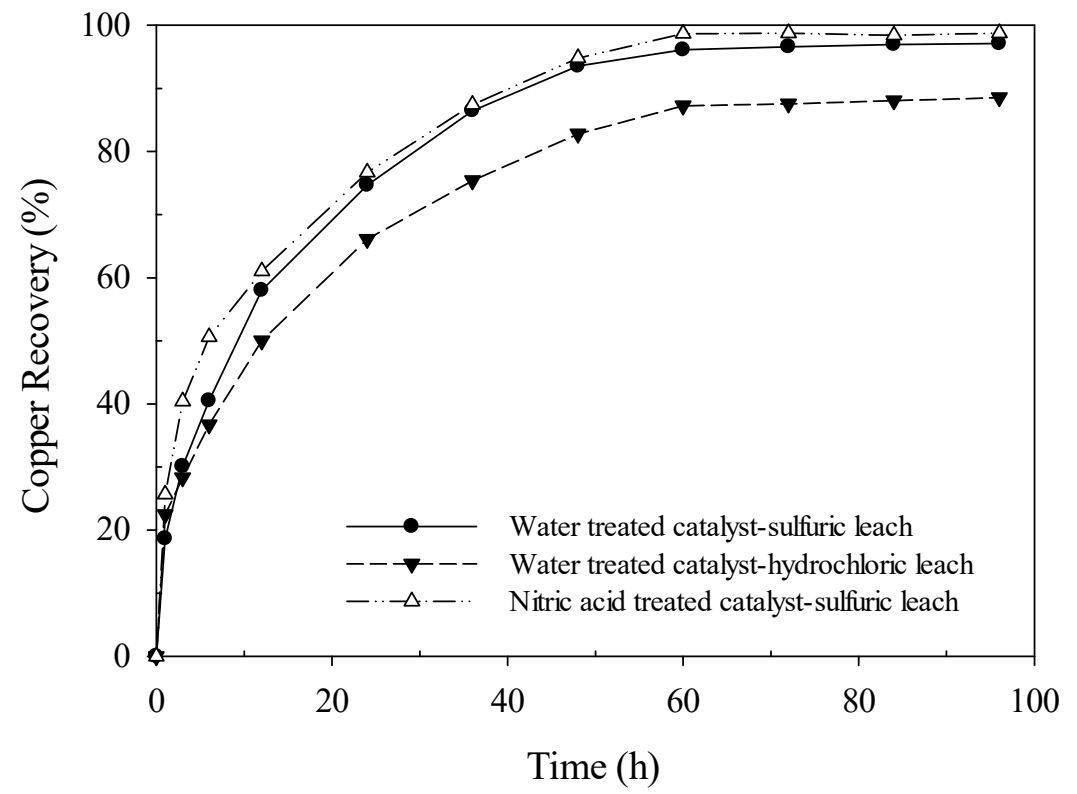

Figure 8. Effect of acid type and catalyst pretreatment on copper recovery.

\subsubsection{In-Situ Arsenic Oxidation with AF 5 Catalyst}

Arsenic is a toxic element which is liberated and solubilized into the leach solution during the copper extraction process from enargite. Ideally, a process should oxidize the solubilized arsenic (often $\left.\mathrm{As}^{3+}\right)$ to its pentavalent state $\left(\mathrm{As}^{5+}\right)$ and immobilize it as scorodite [32]. The use of AF 5 catalyst in enargite leaching makes it possible to immobilize arsenic during the leach process. The type, ionic strength of the dissolution media, and AF 5 pre-treatment process are expected to be important parameters which can affect both the arsenic leaching and the in-situ oxidative precipitation of arsenic, i.e., arsenic immobilization, during the enargite leaching process. It has been shown that arsenic can be immobilized in the enargite leaching process with the following reaction, if the arsenic is present as $\operatorname{As}(\mathrm{V})$ species [32]:

$$
\mathrm{Fe}_{2}\left(\mathrm{SO}_{4}\right)_{3(\mathrm{aq})}+2 \mathrm{H}_{3} \mathrm{AsO}_{4(\mathrm{aq})}+4 \mathrm{H}_{2} \mathrm{O}_{(\mathrm{l})} \rightarrow 2 \mathrm{FeAsO}_{4} \cdot 2 \mathrm{H}_{2} \mathrm{O}_{(\mathrm{s})}+3 \mathrm{H}_{2} \mathrm{SO}_{4(\mathrm{aq})}
$$


Solubility of arsenic species is dependent on the ionic strength and the composition of the leaching media. As illustrated in Figure 9, arsenic leaching kinetics within $96 \mathrm{~h}$ shows two steps for both AF 5 and nitric acid-treated AF 5 in the sulfuric acid solution: (i) a sharp increase in the arsenic recovery within $36 \mathrm{~h}$; (ii) a slow increase in the arsenic dissolution and finally equilibrium was reached. Similar observation has been reported elsewhere [32]. In the case of the AF 5 catalyst which is pre-treated with nitric acid the arsenic extraction into the leach solution at different time intervals was greater than that of the test with water-treated AF 5, likely due to the higher catalytic activity of the oxidized surface of the nitric acid-treated AF 5 and availability of the higher number of functional groups on its surface. As stated previously, three main nitrogen functional groups were found on the surface of the nitric acid-treated catalyst, among those, nitrogen oxidized functionalities are some of the main effective functional groups with the oxidation properties of the CBC. The availability of oxidized nitrogen functionalities would be possibly the main reason for higher arsenic dissolution and oxidation.

The final arsenic dissolution of $87.1 \%$ was achieved when the water-treated AF 5 was used in the leach tests (Figure 9), and the arsenic recovery was $92.1 \%$ when the AF 5 was pre-treated with nitric acid. In addition, no scorodite or other ferric arsenate precipitates were identified in the residue of the sulfate media leach tests. However, in the chloride leach solution, arsenic dissolution initially increased with a steep slope and the maximum arsenic was reached at $48 \mathrm{~h}(70 \%)$. Further increase in the leach time significantly dropped the arsenic concentration, which was assigned to the formation of scorodite/ferric arsenate particles. The critical supersaturation of the chloride media is much lower than that of the sulfate media, thus the formation of scorodite occurs in the chloride leach solution $[33,34]$.

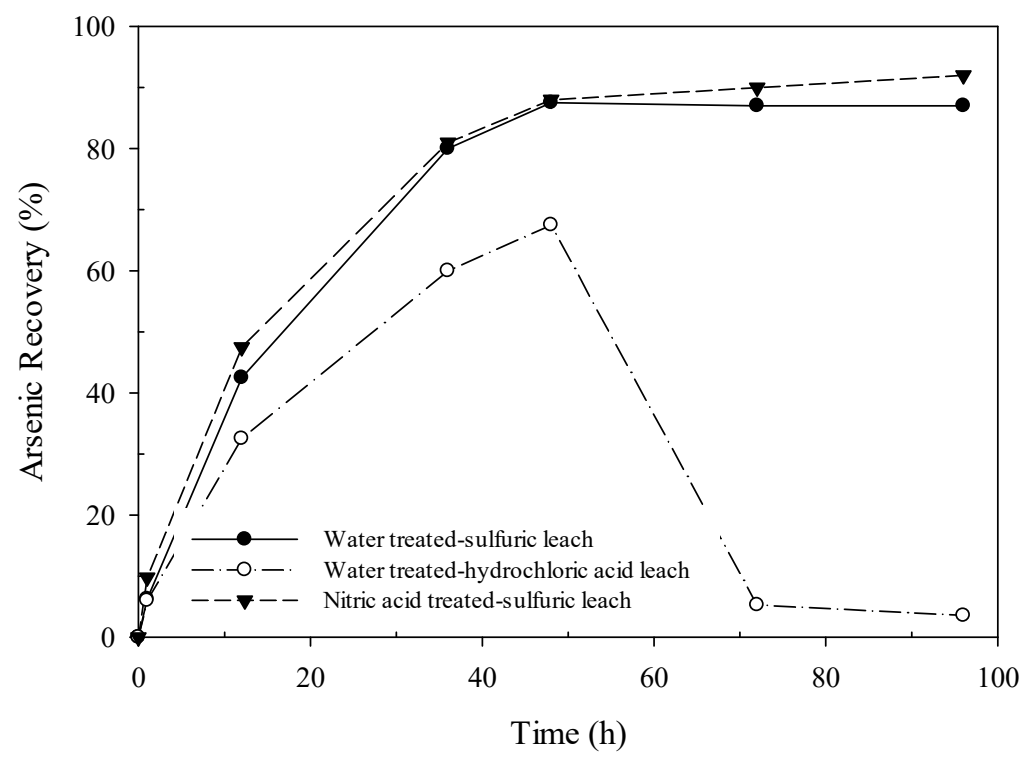

Figure 9. Effect of acid type and catalyst pretreatment on arsenic recovery.

\subsubsection{Elemental Sulfur Adsorption onto AF 5 during Leaching Tests}

One of the advantages of using AF 5 over other $C B C$ for enargite leaching process is the unique property of AF 5 to adsorb elemental sulfur on its surface, i.e., sulfur collection capability. The sulfur adsorption on AF 5 potentially reduces sulfur oxidation to sulfate and consequently decreases the neutralization cost of the generated sulfates and sulfuric acid, usually carried out after the leaching process. In addition, the sulfur removal from the leach residue, via its adsorption onto AF 5, makes the treatment of the residue in the downstream operations simpler (for instance the presence of elemental sulfur in cyanidation circuit can be an issue). The mechanism of the sulfur collection process on AF 5 is not widely well understood yet; however, it might be due to the physical absorption of sulfur to the AF 5 surfaces in its mesoporous, chemical sulfur adsorption by the functional groups or oxidation-reduction of other sulfur by-products on the surface of the catalyst or a combination of the 
different processes [10]. The sulfur balance results in the leaching experiments are provided in Table 6 . The sulfur collection results showed that using a sulfate leach media drastically increased the sulfur yield over sulfate formation. The sulfur collection on the water-treated AF 5 was higher than that on the nitric acid-treated AF 5 by $6 \%$, confirming the free acid titration results. Furthermore, the nitrogen functional groups can increase the desulfurization activity of CBC [29]. The desulfurization effect of the nitrogen functionalities was also observed in the XPS analysis where the overall sulfur content and sulfur peaks declined due to the pretreatment. The sulfate formed in the chloride leaching media was $12.6 \%$ higher than formed in the sulfate media leaching experiments. In summary, the utilization of the sulfuric acid leaching increased the sulfur yield on the surface of the AF 5 catalyst compared to the other treatments.

Table 6. Sulfur balance of the leaching experiments.

\begin{tabular}{lccc}
\hline \multicolumn{1}{c}{ Experiment } & S in Residue (\%) & S in Solution (\%) & S Collected by AF 5 (\%) \\
\hline Water-treated AF 5 hydrochloric acid leach & 16.9 & 51.8 & 30.9 \\
\hline Water-treated AF 5 sulfuric acid leach & 9.5 & 39.2 & 51.1 \\
\hline Nitric acid-treated AF 5 sulfuric acid leach & 0.4 & 54.6 & 45.1 \\
\hline
\end{tabular}

\section{Conclusions}

AF 5 is a carbon-based catalyst which can effectively increase the oxidative leaching kinetics of sulfide minerals, including enargite and pyrite. The catalytic effect of carbon-based catalysts such as AF 5 in leaching processes is attributed to their surface functional groups, and chemical pre-treatment is a viable method to alter the functional groups on the surface of catalysts. In the present study, AF 5 was pre-treated with different acidic solutions and the functional groups on its surface was studied. The AF 5 surface characterization after different chemical pre-treatments confirmed that nitric acid and sulfuric acid pre-treatment processes both could introduce functional groups such as nitrogen and thiol on its surface, as well as increase the oxygen functional groups. The oxygen functional groups that form with the oxidative pre-treatment results in the formation of more oxygen double bonds such as quinone groups which can significantly increase the catalytic capability of AF 5 for oxidation reactions.

The AF 5 catalysts with different pre-treatments were used in enargite leaching tests. The nitric acid pre-treated AF 5 showed superior enargite leaching catalytic properties, where $98.8 \%$ copper and 93.8\% iron could be recovered into the pregnant leach solution. However, the precipitation of arsenic in the form of scorodite solely occurred in the leaching tests in the chloride media. In addition, the sulfuric acid leaching led to the $97.1 \%$ of copper recovery as well as a pyrite oxidation of about $82.5 \%$. The lowest copper recovery was obtained in the leaching tests in the chloride media, with only $88.6 \%$ $\mathrm{Cu}$ recovery. The lower dissolution of enargite in chloride media is due to the lower catalytic activity of $\mathrm{CBC}$ caused by lower concentrations of oxygen and nitrogen functional groups.

One unique property of AF 5 is its sulfur adsorption on the surface. More elemental sulfur was collected on AF 5 when the leach tests were carried out in sulfuric acid solution and the AF 5 was pre-treated in sulfuric acid. The higher yield of elemental sulfur is a result of the increased concentration of oxygen functional groups in sulfuric acid leaching process and improved collection of elemental sulfur on the $\mathrm{CBC}$ surface might be caused by the chain adsorption of elemental sulfur via sulfur containing surface groups. It is believed that the sulfur adsorption to AF 5 potentially occurs by the chemical or physical adsorption of meta-stable polysulfide groups on the surface of the catalyst. In general, the use of nitric acid pre-treated AF 5 and sulfuric acid-based leaching media are beneficial to achieve higher copper recovery; use of sulfuric acid enhanced the elemental sulfur generation and its collection on AF 5 during leaching process. Based on the XPS spectra of the post leaching catalyst surface, the nitrogen functionalities concentration, specially oxidized nitrogen functionalities, were reduced on the surface of the nitric acid pre-treated AF 5, likely due to the adsorption of elemental sulfur on the AF 5 surfaces. 
Author Contributions: Conceptualization, F.G.J. and A.G.; Data curation, F.G.J.; Formal analysis, F.G.J.; Funding acquisition, A.G.; Investigation, F.G.J.; Methodology, F.G.J. and A.G.; Writing—original draft, F.G.J.; Writing-review \& editing, A.G.

Funding: This research was funded by Natural Sciences and Engineering Research Council of Canada (NSERC) Discovery Grant, grant number RGPIN-2015-05718.

Conflicts of Interest: The authors declare no conflict of interest. The funders had no role in the design of the study; in the collection, analyses, or interpretation of data; in the writing of the manuscript, and in the decision to publish the results.

\section{References}

1. Jahromi, F.G.; Cowan, D.H.; Ghahreman, A. Lanxess Lewatit ${ }^{\circledR}$ AF 5 and activated carbon catalysis of enargite leaching in chloride media; a parameters study. Hydrometallurgy 2017, 174, 184-194. [CrossRef]

2. Cowan, D.H.; Jahromi, F.G.; Ghahreman, A. Atmospheric oxidation of pyrite with a novel catalyst and ultra-high elemental sulphur yield. Hydrometallurgy 2017, 173, 156-169. [CrossRef]

3. Montes-Morán, M.A.; Suárez, D.; Menéndez, J.A.; Fuente, E. On the nature of basic sites on carbon surfaces: An overview. Carbon N. Y. 2004, 42, 1219-1225. [CrossRef]

4. Andreas, H.A.; Conway, B.E. Examination of the double-layer capacitance of an high specific-area C-cloth electrode as titrated from acidic to alkaline pHs. Electrochim. Acta 2006, 51, 6510-6520. [CrossRef]

5. Karatepe, N.; Orbak, I.; Yavuz, R.; Özyuğuran, A. Sulfur dioxide adsorption by activated carbons having different textural and chemical properties. Fuel 2008, 87, 3207-3215. [CrossRef]

6. Hulicova-Jurcakova, D.; Seredych, M.; Lu, G.Q.; Bandosz, T.J. Combined effect of nitrogen- and oxygen-containing functional groups of microporous activated carbon on its electrochemical performance in supercapacitors. Adv. Funct. Mater. 2009, 19, 438-447. [CrossRef]

7. Shim, J.W.; Park, S.J.; Ryu, S.K. Effect of modification with $\mathrm{HNO} 3$ and $\mathrm{NaOH}$ on metal adsorption by pitch-based activated carbon fibers. Carbon N. Y. 2001, 39, 1635-1642. [CrossRef]

8. Fu, K.; Yue, Q.; Gao, B.; Wang, Y.; Li, Q. Activated carbon from tomato stem by chemical activation with $\mathrm{FeCl}_{2}$. Colloids Surf. A Physicochem. Eng. Asp. 2017, 529, 842-849. [CrossRef]

9. Prestidge, C.A.; Thiel, A.G.; Ralston, J.; Smart, R.S.C. The interaction of ethyl xanthate with copper(II)_Activated zinc sulphide: Kinetic effects. Colloids Surf. A Physicochem. Eng. Asp. 1994, 85, 51-68. [CrossRef]

10. Bandosz, T.J.; Ania, C.O. Activated Carbon Surfaces in Environmental Remediation. Interface Sci. Technol. 2006, 7, 159-229. [CrossRef]

11. Mangun, C.L.; DeBarr, J.A.; Economy, J. Adsorption of sulfur dioxide on ammonia-treated activated carbon fibers. Carbon N. Y. 2001, 39, 1689-1696. [CrossRef]

12. Boudou, J.-P.P.; Chehimi, M.; Broniek, E.; Siemieniewska, T.; Bimer, J. Adsorption of $\mathrm{H}_{2} \mathrm{~S}$ or $\mathrm{SO}_{2}$ on an activated carbon cloth modified by ammonia treatment. Carbon N. Y. 2003, 41, 1999-2007. [CrossRef]

13. Rosas, J.M.; Ruiz-Rosas, R.; Rodríguez-Mirasol, J.; Cordero, T. Kinetic study of $\mathrm{SO}_{2}$ removal over lignin-based activated carbon. Chem. Eng. J. 2017, 307, 707-721. [CrossRef]

14. Sun, F.; Gao, J.; Liu, X.; Tang, X.; Wu, S. A systematic investigation of $\mathrm{SO}_{2}$ removal dynamics by coal-based activated cokes: The synergic enhancement effect of hierarchical pore configuration and gas components. Appl. Surf. Sci. 2015, 357, 1895-1901. [CrossRef]

15. Bai, B.C.; Lee, C.W.; Lee, Y.S.; Im, J.S. Metal impregnate on activated carbon fiber for $\mathrm{SO}_{2}$ gas removal: Assessment of pore structure, $\mathrm{Cu}$ supporter, breakthrough, and bed utilization. Colloids Surf. A Physicochem. Eng. Asp. 2016, 509, 73-79. [CrossRef]

16. Ahumada, E.; Lizama, H.; Orellana, F.; Suarez, C.; Huidobro, A.; Seoulveda-Escribano, A.; Rodriquez-Reinoso, F. Catalytic oxidation of Fe (II) by activated carbon in the presence of oxygen. Effect of the surface oxidation degree on the catalytic activity. Carbon N. Y. 2002, 40, 2827-2834. [CrossRef]

17. Biniak, S.; Szymański, G.; Siedlewski, J.; Światkoski, A. The characterization of activated carbons with oxygen and nitrogen surface groups. Carbon N. Y. 1997, 35, 1799-1810. [CrossRef]

18. Sun, Z.; Chai, L.; Shu, Y.; Li, Q.; Liu, M.; Qiu, D. Chemical bond between chloride ions and surface carboxyl groups on activated carbon. Colloids Surf. A Physicochem. Eng. Asp. 2017, 530, 53-59. [CrossRef] 
19. Wang, Q.; Lei, X.; Pan, F.; Xia, D.; Shang, Y.; Sun, W.; Liu, W. A new type of activated carbon fibre supported titanate nanotubes for high-capacity adsorption and degradation of methylene blue. Colloids Surf. A Physicochem. Eng. Asp. 2018, 555, 605-614. [CrossRef]

20. Lu, X.; Jiang, J.; Sun, K.; Zhu, G.; Lin, G. Enhancement of $\mathrm{Pb}^{2+}$ removal by activating carbon spheres/activated carbon composite material with $\mathrm{H}_{2} \mathrm{O}$ vapor. Colloids Surf. A Physicochem. Eng. Asp. 2016, 506, 637-645. [CrossRef]

21. Pevida, C.; Plaza, M.G.; Arias, B.; Fermoso, J.; Rubiera, F.; Pis, J.J. Surface modification of activated carbons for $\mathrm{CO}_{2}$ capture. Appl. Surf. Sci. 2008, 254, 7165-7172. [CrossRef]

22. Chingombe, P.; Saha, B.; Wakeman, R.J. Surface modification and characterisation of a coal-based activated carbon. Carbon N. Y. 2005, 43, 3132-3143. [CrossRef]

23. Shin, S.; Jang, J.; Yoon, S.-H.; Mochida, I. A study on the effect of heat treatment on functional groups of pitch based activated carbon fiber using FTIR. Carbon N. Y. 1997, 35, 1739-1743. [CrossRef]

24. Terzyk, A.P. The influence of activated carbon surface chemical composition on the adsorption of acetaminophen (paracetamol) in vitro. Part II. TG, FTIR, and XPS analysis of carbons and the temperature dependence of adsorption kinetics at the neutral pH. Colloids Surf. A Physicochem. Eng. Asp. 2001, 177, $23-45$. [CrossRef]

25. Zhou, J.H.; Sui, Z.J.; Zhu, J.; Li, P.; Chen, D.; Dai, Y.C.; Yuan, W.K. Characterization of surface oxygen complexes on carbon nanofibers by TPD, XPS and FT-IR. Carbon N. Y. 2007, 45, 785-796. [CrossRef]

26. Kundu, S.; Wang, Y.; Xia, W.; Muhler, M. Thermal Stability and Reducibility of Oxygen-Containing Functional Groups on Multiwalled Carbon Nanotube Surfaces: A Quantitative High-Resolution XPS and TPD/TPR Study. J. Phys. Chem. C 2008, 112, 16869-16878. [CrossRef]

27. Puziy, A.M.; Poddubnaya, O.I.; Socha, R.P.; Gurgul, J.; Wisniewski, M. XPS and NMR studies of phosphoric acid activated carbons. Carbon N. Y. 2008, 46, 2113-2123. [CrossRef]

28. Figueiredo, J.L.; Pereira, M.F.R.; Freitas, M.M.; Órfão, J.J.M. Modification of the surface chemistry of activated carbons. Carbon N. Y. 1999, 37, 1379-1389. [CrossRef]

29. Figueiredo, J.L.; Pereira, M.F.R. The role of surface chemistry in catalysis with carbons. Catal. Today 2010, 150, 2-7. [CrossRef]

30. Safarzadeh, M.S.; Moats, M.S.; Miller, J.D. An Update to "Recent Trends in the Processing of Enargite Concentrates". Miner. Process. Extr. Metall. Rev. 2012, 35, 390-422. [CrossRef]

31. Ruiz, M.C.; Vera, M.V.; Padilla, R. Mechanism of enargite pressure leaching in the presence of pyrite. Hydrometallurgy 2011, 105, 290-295. [CrossRef]

32. Jahromi, F.G.; Ghahreman, A. In-situ oxidative arsenic precipitation as scorodite during carbon catalyzed enargite leaching process. J. Hazard. Mater. 2018, 360, 631-638. [CrossRef] [PubMed]

33. Demopoulos, G.P. Aqueous precipitation and crystallization for the production of particulate solids with desired properties. Hydrometallurgy 2009, 96, 199-214. [CrossRef]

34. le Berre, J.F.; Gauvin, R.; Demopoulos, G.P. A study of the crystallization kinetics of scorodite via the transformation of poorly crystalline ferric arsenate in weakly acidic solution. Colloids Surf. A Physicochem. Eng. Asp. 2008, 315, 117-129. [CrossRef]

(C) 2019 by the authors. Licensee MDPI, Basel, Switzerland. This article is an open access article distributed under the terms and conditions of the Creative Commons Attribution (CC BY) license (http://creativecommons.org/licenses/by/4.0/). 